* Doutor e Mestre em Direito Público pela Universidade do Vale do Rio dos Sinos (UNISINOS); Bolsista PROEX/CAPES no Mestrado e Doutorado; Membro do Grupo de Pesquisa Estado e Constituição e da Rede Interinstitucional de Pesquisa Estado e Constituição, vinculados a FDV/ES, a ESDHC/ MG e ao CNPQ; Professor Adjunto I do Departamento de Direito da Universidade Federal de Santa Maria (UFSM); Especialista em Direito: Temas Emergentes em Novas Tecnologias da Informação e Bacharel em Direito pelo Centro Universitário Franciscano (UNIFRA). E-mail: ferdhoffa@ yahoo.com.br

**Bacharel em Direito pela Universidade Regional Integrada do Alto Uruguai e das Missões (URI/Câmpus Santiago). E-mail: jucielleflores@gmail.com

\section{Estado-naÇão, Biopolítica e Fenômeno Migratório: o Reconhecimento do Migrante Frente ao Cenário Biopolítico}

\author{
Nation-State, Biopolitics and Migratory Phenomenon: \\ the Recognition of the Migrant Against the \\ Biopolitical ScENARio
}

\section{Fernando Hoffmam* Juciélle Flores Marques**}

Como citar: HOFFMAM, Fernando; MARQUES, Juciélle Flores. Estado-nação, biopolítica e fenômeno migratório: o reconhecimento frente ao cenário biopolítico. Revista do Direito Público, Londrina, v. 15, n. 1, p. 114-136, abr. 2020. DOI: 10.5433/24157-108104-1.2020v15n1p. 114. ISSN: 1980-511X

Resumo: A presente pesquisa tem como objetivo o estudo sobre o reconhecimento do outro enquanto sujeito de direitos no Estado-nação, acerca do fenômeno migratório frente ao cenário biopolítico. Devido ao fato de a mobilidade humana transcender as fronteiras, o espaço de ação do migrante questiona os limites e funções do Estado, tanto no que concerne sua recepção ao corpo social, quanto aos requisitos para enquadrar-se enquanto detentor do direito a ter direitos. O espaço do migrante não é o espaço Estatal, mas nele produz diferentes formas de interação e demanda ampliação, redefinindo suas estruturas, o que pressupõe a compreensão da complexidade de relações que o fluxo migratório carrega. Assim, pretende-se analisar a compreensão do migrante enquanto sujeito de direitos perante o cenário biopolítico, e a concretização da universalidade dos Direitos Humanos, frente ao Estado nacionalista.

Palavras-chave: Estado. Nacionalismo. Biopolítica. Migração. Direitos humanos.

Abstract: This research studies the recognition of the other as a subject of rights in the nation-state and explores the phenomenon of migration in our biopolitical society. Due to the fact that humans are mobile and, therefore, naturally cross borders, migrants question the limits and functions of the State, both in regards to a countries willfulness to accept migrants and give them the right to have rights. The space of the migrant is not the same as the State's space, yielding different forms of subject interaction. Moreover, this phenomenon demands rigorous analysis, as a means for redefining its structures, which presupposes the understanding of 
complex relationships of migratory flow patterns. Therefore, this paper analyzes migrants as subjects of rights in our biopolitical scenario, and the realization of the universality of Human Rights, before the nationalist State.

Keywords: State. Nationalism. Biopolitics. Migration. Human Rights. 


\section{INTRODUÇÃO}

O presente trabalho tem como propósito analisar o reconhecimento do outro enquanto sujeito de direitos frente ao cenário biopolítico imposto pelo Estado-nação, observando os mecanismos de manutenção da soberania Estatal baseados na estratégia nacionalista, e a sua interferência no cenário de recepção ao fenômeno migratório.

Diante desse contexto, a compreensão do migrante enquanto sujeito de direitos é restringida, sendo que, a partir da ótica nacionalista, a constituição político-social Estatal ocorre de forma unitária, visando institucionalizar o medo do outro e o combate à diversidade. Assim, o migrante é enquadrado por um ordenamento jurídico no qual é incluído para definitivamente ser excluído. Frente a esse cenário, questiona-se: é possível a concretização da universalidade dos Direitos Humanos e a compreensão do migrante como sujeito de direitos, sendo os instrumentos jurídicos para tal fruto de um Estado nacionalista?

Perante o enquadramento biopolítico imposto pelo Estado-nação, fomenta-se a ideia de unidade, e também, a necessidade de proteger fronteiras, legitimando a restrição dos movimentos migratórios e violações de Direitos Humanos. Com isso, para que a universalidade dos Direitos Humanos seja concretizada, e o migrante reconhecido enquanto sujeito de direitos, faz-se necessário que a soberania Estatal seja exercida de forma internacionalista, respeitando o pluralismo humano.

Assim, o presente trabalho tem como objetivo estudar o fenômeno migratório a partir dos Direitos Humanos frente ao cenário de biopolítica, em que a condição humana é diluída pelo político e apropriada pelo Estado, ainda, visa compreender a influência do nacionalismo no exercício da soberania Estatal, e o reconhecimento do migrante como sujeito de direitos frente ao Estado nacionalista.

Dessa forma, analisa-se a constituição do Estado, sua conceituação, estruturação e suas funções, bem como, o controle sobre seu corpo social e sua transição para a instituição nacionalista, observando a interferência do nacionalismo nos mecanismos disciplinadores do sistema Estatal (Parte 1).

Em um segundo momento, será analisado o enquadramento biopolítico e a consequente politização da vida natural, que é absorvida pela estrutura político-Estatal, que se apropria de sua condição humana, a utilizando como estratégia de manutenção da soberania do Estado (Parte 2).

Nesse caminho, busca-se o estudo do fenômeno migratório tendo como foco a recepção do migrante e seu reconhecimento enquanto sujeito social e de direitos perante o corpo políticoEstatal, analisando o paradigma da pertença e os requisitos necessários ao enquadramento enquanto cidadão, da mesma forma, observa-se a concretização da universalidade dos Direitos Humanos e a efetiva participação do migrante em sociedade (Parte 3).

$\mathrm{O}$ método de abordagem foi o dedutivo, uma vez que, de forma geral analisou-se a influência do nacionalismo na estruturação do Estado-nação; e de forma específica, se observou a sua interferência no que tange o reconhecimento do migrante como sujeito de direitos, e na concretização da universalidade dos Direitos Humanos. O método de procedimento foi o 
monográfico, já que, a pesquisa foi baseada em obras de autores que se detém ao assunto objeto da pesquisa. Por fim, a técnica de pesquisa foi a de documentação indireta, pois a pesquisa embasouse em livros, artigos científicos, revistas jurídicas e a legislação pertinente.

Pelo exposto, evidencia-se a relevância do presente tema pelas reflexões acerca do cenário biopolítico imposto pelo Estado nacionalista, e a sua interferência no que tange a concretização da universalidade dos Direitos Humanos. Destaca-se também, o exercício da soberania Estatal de forma unitária e seus reflexos no reconhecimento do outro enquanto sujeito de direitos frente ao fenômeno migratório.

\section{A CONSTRUÇÃO DO ESTADO-NAÇÃO A PARTIR DO NACIONALISMO}

O ente Estatal é reconhecido como um corpo político que exerce o poder soberano sobre sua coletividade social, em que a essência do seu domínio no exercício governamental reside em sua aptidão em persuadir seu corpo social, em reger as relações coletivas internas e, em sustentar e expandir o seu controle nas relações externas. Em virtude destes artifícios, a estrutura Estatal desempenha um controle autocentrado dos mecanismos disciplinadores perante a conjuntura político-social.

Nesse sentido, o Estado surge da necessidade de reconhecimento político e organização administrativa de um povo, gerando um pacto social em que o assegura liberdades e direitos. O processo de vinculação entre sujeito e órgão Estatal visa à constituição de um povo unitário, soberano e autossuficiente, embasando-se em métodos identitários, estabelecendo padrões de identificação, fomentando a institucionalização do paradigma da pertença, baseando-se nos interesses e liberdades individuais, originando um cenário coletivo interno de relações sociais privativas.

Diante deste contexto, a constituição do poder político Estatal se fez através de uma operação jurídica contratual, em que o povo cedeu, total ou parcialmente, o poder de autonomia que detinha, fundando uma soberania política. Desta forma, o Estado se autoinstitui, impõe sua figura perante o corpo social, dando origem a uma nova ordem política, em que o ente Estatal expressa a vontade geral, e o povo adquire característica de uniformidade, visando manter a estabilidade do arranjo segregatório de subordinação.

O Estado enquanto ente soberano detém o monopólio da decisão, nisto reside à essência da soberania Estatal, que, portanto, não é definida como monopólio do poder (AGAMBEN, 2014), mas sim, como monopólio da delimitação e determinação do produto da atividade humana que a ele está subordinado. Assim, ao reduzir o sujeito a um produto da relação político-jurídica, ignorase sua pessoalidade, produzindo uma coletividade limitada à característica unitária, formando um povo homogêneo, que ao ter sua individualidade restringida, passa a conceber-se na totalidade do corpo Estatal.

Nesse passo, é importante delimitar o começo da forma estatal a partir das ideias de Thomas Hobbes. Hobbes aposta na radicalização do individualismo, ao mesmo tempo em que ele 
aposta no surgimento de uma autoridade maior que faz com que os indivíduos abram mão de uma parte de sua liberdade para sujeitar-se ao poder soberano de uma pessoa que os representa de forma legitima por um comum acordo (HOBBES, 2014).

Eis que se forma a ideia hobesiana do grande Leviatã, o Estado absolutista que toma nas suas mãos as rédeas da organização política, jurídica e social, retirando do estado de natureza os sujeitos e os organizando racionalmente sob um mesmo signo que os representa. Hobbes coloca a ideia de garantia da liberdade como central para a cessão de soberania a um terceiro, mas, ao mesmo tempo, relativiza essa liberdade individual ao cedê-la para o poder soberano.

O soberano criado pela via do pacto constituído entre todos, entre a multidão, nasce também com as características do direito natural e nos interesses do homem moderno e de sua racionalidade constitutiva de toda a sua humanidade. Nasce uma figura imanente que, embora sujeite todos os indivíduos sobre as suas regras, não se coloca sujeito às mesmas, pairando paradoxalmente como algo transcendente que garante a felicidade e os direitos de todos os súditos (DOUZINAS, 2009).

Desse modo, já na sua criação se mostra contraditório o Leviatã, haja vista que ao instituirse enquanto poder supremo, o soberano acaba por desmoronar a construção jusnatural no que tange aos súditos que acabam por ficar sujeitos ao poder central do soberano constituído à imagem do indivíduo e tendente à sua racionalidade. Os súditos abrem mão de seu poder para a manutenção da vida e, com esse poder, permitir-se utilizar de qualquer meio para garantir o seu modo de vida - eis a liberdade de agir em consonância com o seu princípio de vida. "O reconhecimento e a proteção do direito natural prepara o seu desaparecimento. Nessa medida, o direito natural é sempre protelado, uma miragem ou mecanismo heurístico que explica a criação da política moderna" (DOUZINAS, 2009, p. 93).

O poder soberano aqui não sofre qualquer limitação e como fica explicito não se compatibiliza necessariamente - pelo menos - com a função de garante dos direitos naturais adquiridos pelos indivíduos a partir da razão que lhes confere autonomia. Os limites do Estado são demarcados pela ação em defesa da própria estatalidade que se absolutiza enquanto instituição central dessa recente modernidade (BOLZAN DE MORAIS, 2011).

No momento em que o povo passa a se conceber como parte integrante da constituição Estatal, entende-se como equivalente a ela, não reconhecendo sua potencialidade enquanto corpo político-comunitário. O Estado, ao constatar tamanha força e capacidade organizacional disposta no meio social, as absorve e manipula, obstruindo suas formas de articulação, impondo uma ficção de unicidade, visando neutralizar a possibilidade de qualquer forma de insubordinação.

A partir disso, instaurou-se um processo de homogeneização Estatal, que aniquilou a multiplicidade de características que compõem o sujeito, suprimiu as relações coletivas ao fomentar a constituição de um corpo social unitário, o transformando em um "certo número de individualidades separadas, que se encontram reunidas por certo número de elementos constitutivos do Estado" (FOUCAULT, 2008, p. 34). Desta forma, a conjuntura Estatal utiliza mecanismos advindos de movimentos totalitários, que são viáveis em qualquer lugar em que existam massas.

O poder soberano Estatal consiste no domínio em relação ao seu objeto-alvo, que 
é a subordinação das massas, assim, o Estado possui em si uma espécie de força de expansão, constituindo um lugar-comum em que manipula a conduta humana, garantindo a manutenção da sua governabilidade (FOUCAULT, 2008). Para assegurar sua estabilidade no exercício do sistema político favorável à sua soberania, em regra, o Estado constitui-se de forma fixa, baseando-se em seu território.

A organização fixa e unitária do Estado permite a continuidade, e ao mesmo tempo, a inserção de novas camadas sob o seu domínio, sem que lhe altere a estrutura, por isso, é essencial para a estratégia separatista e autoritária Estatal, a institucionalização do sistema unitário social. Desta maneira, o modelo tradicional de Estado restringe o desenvolvimento das relações sociais, impondo a relação de dominação política em todas as esferas da vida humana.

Devido a esta dominação, ao Estado é "concedido o controle sobre o desenvolvimento social" (HARDT; NEGRI, 2001, p. 112), pois, ele representa a garantia de paz e segurança à sociedade. Desta forma, há o controle da expansão da coletividade, propiciando a absorção desse processo por seus mecanismos de poder, vinculado ao domínio territorial. Em vista disso, a soberania Estatal se torna fundamentalmente atrelada ao território, fazendo com que a massificação do sujeito seja substituída pelo processo de associação nacional.

A união do nacional com o Estado vinculou a nação ao território, tendo em vista uma estrutura Estatal essencialmente territorial. É essencial para a efetividade deste modelo unitário que o território seja inviolável e, controlado pelo Estado, assim, ele é tido como figura segura à nação, e detém a função de manter a estabilidade interna requerida pelos nacionais, reforçando a tríade soberania-nação-território. Desta forma, o território desempenha importante papel no processo de vinculação entre nação e Estado.

Em decorrência desse processo, origina-se um sistema político que almeja a efetivação do legítimo interesse do Estado, ou seja, espera que os movimentos nacionalistas sejam movimentos que visem à expansão e unificação nacional, isto é, fabrica-se a nação (HOBSBAWM, 2002). Por conseguinte, funda-se uma estrutura Estatal nacionalista, que é consolidada a partir da união do nacionalismo com o poder soberano do Estado, visando uma constituição interna, una e indivisa.

Essa relação homogênea assegura aos nacionais a garantia da defesa dos interesses comuns e, a sua manutenção enquanto comunidade soberana, resguardando seus laços identitários, ou seja, o Estado se encarrega de manter a unidade e orgulho da nação, reforçando a ideia de autossuficiência. Assim, a nação se consolida como um grupo subordinado, que desempenha uma função defensiva, utilizada na defesa do território Estatal contra a interferência externa, por meio de um fator de unicidade (HOBSBAWM, 2002).

"De todas as formas de governo e organização de povos, o Estado-nação é a que menos se presta ao crescimento ilimitado" (ARENDT, 2017b, p. 194), já que, baseia-se no reconhecimento e consentimento da nação, logo, não se expande para além do próprio grupo nacional. Assim, a estrutura Estatal hesitou a se enquadrar no arranjo nacionalista, devido ao fato de sua condição ser imprevisível, pois, da mesma maneira que o nacional apoia sua constituição, ele pode se opor a ela.

Por isso, ao instituir o nacionalismo no plano governamental, gerou-se um processo de 
vinculação entre nação e território, objetivando garantir sua imutabilidade e autossuficiência, formando a figura de um Estado autônomo, capaz de garantir e promover a harmonização dos interesses individuais, enquanto composição coletiva, ou seja, o nacional se sujeita ao domínio Estatal, a tal ponto, que o concebe como fonte de poder autêntica. Desta forma, sutilmente, instaurase a tradição nacional inventada, que determina "certos valores e normas de comportamento através da repetição, o que implica, automaticamente, uma continuidade em relação ao passado" (HOBSBAWM; RANGER, 2008, p. 9). Através dessa repetição constante, a estrutura Estatal nacionalista se consolida como sendo advinda de uma ordem natural, o que legitima sua constituição e manutenção de seu domínio.

Contudo, essa tradição inventada, contrasta-se com as pluralidades das evoluções sociais, o que impossibilita a estruturação Estatal de forma invariável. Por isso, fez-se necessária a implementação de uma ideologia permanente, pois assim, independentemente de qualquer heterogeneidade e modificação interna, tem-se a automatização de práticas discursivas enraizadas no cotidiano social, que asseguram a materialidade da imprescindibilidade da instituição Estatal.

Desta maneira, promove-se a ideia da busca de um interesse único, concebendo o corpo social e o corpo Estatal como equivalentes. É crucial para a estratégia nacionalista o sentimento de unidade e pertencimento do sujeito, pois assim, o processo de dominação imposto, aparenta ser meramente a harmonização de interesses, fomentando-se uma tradição que se perpetua de forma una e linear, reforçando o vínculo entre a conjuntura Estatal e o corpo social. Diante deste contexto, pode-se dizer que o propósito da estrutura nacionalista Estatal, é fazer com que os nacionais sejam vulneráveis no âmbito político-social, e acreditem no desenvolvimento de forças sociais unitárias, pois, desta maneira, formariam um povo soberano as questões externas, mas subordinados em ralação as demandas internas.

Assim, o nacional acredita ser parte integrante ativa do corpo Estatal, já que, nele se reconhece e, concebe a sua legitimidade de agir como expressão de seu próprio interesse. Essa percepção de semelhança permite ao ente Estatal reger sua política governamental baseado em sua delimitação territorial, mantendo o engajamento do nacional em proteger as fronteiras, visando resguardar a composição social unitária, eliminando, tanto quanto possível, as heterogeneidades, idealizando um cenário de estabilidade interna.

Desta forma, "a política organiza, de antemão, as diversidades absolutas de acordo com uma igualdade relativa e em contrapartida às diferenças relativas" (ARENDT, 2002, p. 7). O domínio territorial legitima o controle Estatal sobre o produto das relações sociais, mantém a relação entre dominador e dominado, assegurando este domínio com base em uma imposição velada, fazendo com que o nacional o conceba como detentor da vontade social expressa na política geral.

No momento em que esta política se torna imprescindível para a manutenção das relações sociais, verifica-se a incapacidade da coletividade em reger sua própria vinculação, ou seja, o Estado utiliza esta fragmentação e individualização para impor mecanismos de sujeição ao seu regime governamental. Por este motivo, o poder soberano Estatal delimita quem faz parte ou não da constituição do seu corpo social, valendo-se de uma presunção de superioridade desse seleto 
grupo. Esse movimento é crucial para a base do Estado-nação, que ao exercer seu poder de forma absolutista, fomenta sua independência e autossuficiência, assim, sua soberania também pode ser entendida como o conjunto de capacidades, possibilidades e potências, que se tornam a unidade do poder político. Em decorrência da necessidade de manutenção deste poder unitário, a estratégia de proteção das fronteiras é incorporada a organização governamental.

Desse modo, consolida-se uma constituição soberana territorial, em que o ser humano é delimitado em desejável ou indesejável por intermédio das fronteiras, segregando o espaço público, e restringindo o reconhecimento do sujeito como ser político e social. Objetiva-se anular toda e qualquer interferência externa sob o domínio de seu território, consolidando uma estrutura unificada e segura em si, em que o ente Estatal transfere para sua extensão territorial uma função uniformizadora.

Frente a este cenário, as fronteiras figuram como um elemento inquietante à soberania nacional, pois ameaçam seu controle interno, obrigando o Estado, de certa forma, a flexibilizar seu mecanismo disciplinador, já que, o exercício de sua governabilidade se encontra restringido a este espaço delimitado, e ao mesmo tempo, sujeito a inserção de novos elementos sob seu domínio. Assim, visando fixar a legitimidade de seu poder, o ente Estatal institucionalizou o combate à diversidade, e a necessidade de proteger suas fronteiras.

Desta forma, se evidencia a possibilidade de variação estrutural Estatal, por isso, "o Estado é ao mesmo tempo o que existe e o que ainda não existe suficientemente" (FOUCAULT, 2008 , p. 6), pois o seu caráter contínuo e fixo depende diretamente do consentimento de seus subordinados, ou seja, a expressividade política contida no corpo social detém a capacidade de modificar esta estrutura, no entanto, é alienada e aniquilada através do processo de absorção e uniformização Estatal.

A condição humana é diluída pelo político e apropriada pelo Estado, originando um sujeito territorializado, em que a nacionalidade é tida como forma de inscrição primária da vida na ordem Estatal, e sua pessoalidade é absorvida pelos mecanismos disciplinadores, devido ao sistema de exercício governamental. Este processo de apropriação rege as relações entre os sujeitos e simultaneamente a relação entre sujeito e Estado, ou seja, este domínio sobre a vida natural caracteriza o controle biopolítico exercido pela máquina estatal sobre os seus súditos.

Perante o exposto, pode-se observar que a constituição Estatal, apesar da evolução histórico-social, manteve-se fundada nos antagonismos de classes, frente a um cenário em que a individualidade institucionalizada se consolida, fomentando a perpetuação das relações entre dominador e dominado. Dessa forma, o seu corpo social tem sua vida natural politizada e reduzida ao corpo nacional, sendo o controle biopolítico enquadrado como estratégia de manutenção da soberania Estatal.

\section{A POLITIZAÇÃO DA VIDA E O ENQUADRAMENTO BIOPOLÍTICO COMO ESTRATÉGIA DE MANUTENÇÃO DA SOBERANIA ESTATAL}


A essência do poder governamental consiste na sua capacidade de moldar a vida natural do sujeito, ou seja, produzir ou destruir seu corpo constituinte, o politizando e o dominando, o incorporando aos seus mecanismos estruturais, pois assim, impõe a supremacia de seus interesses. A estratégia de politização da vida enquadra o sujeito nos limites de dominação Estatal, absorvendo e se apropriando de sua pessoalidade, transformando a vida natural em um instrumento de poder e, simultaneamente, em uma forma de poder.

O sujeito, ao ser enquadrado pelo aparelho Estatal, é disciplinado pelo sistema de controle governamental, que desenvolve a organização do poder sobre a vida. "Tais processos são assumidos mediante toda uma série de intervenções e controles reguladores: uma bio-política da população" (FOUCAULT, 1999b, p. 131), assim, o sistema de dominação imposto pelo Estado reside em sua aptidão em manipular a conduta do seu corpo social, instituindo uma relação política em todas as esferas da vida humana.

Ao se analisar a relação entre Estado e corpo social, observa-se que o poder político não é algo absoluto, mas sim, uma potência que se desenvolve conforme as relações sociais, tendo a população como objeto-alvo. Essas relações de poder não são de ordem natural, ocorrem devido à intervenção disciplinadora Estatal, dessa forma, a relação entre os sujeitos constituintes desta estrutura é o que origina a figura do corpo subordinado e do ente soberano.

Michel Foucault definia como biopolítica as implicações da vida natural humana nos mecanismos e formas de poder (AGAMBEN, 2014), ou seja, é a interferência política sobre todos os aspectos da vida humana. Esse paradigma biopolítico transformou a vida natural em uma forma de poder, a tornando um objeto de domínio político, em que o sujeito é tanto alvo quanto instrumento em uma relação de dominação e subordinação à soberania Estatal.

No momento em que o sujeito tem sua vida natural absorvida pelos mecanismos de poder governamental, o poder não se aplica a ele, mas sim, passa por ele, ou seja, o sujeito não é mais o outro na relação de dominação, quando dominado transforma-se em um efeito dela. Dessa forma, a política geral baseia-se e fomenta a perspectiva biopolítica, visando abranger a totalidade das relações internas, tanto entre o próprio corpo social, quanto do corpo social com o ente Estatal.

Por conseguinte, as implicações da vida natural passam a ter valor político, reduzindo o sujeito a um mero objeto de produção e manipulação do Estado soberano, o que culmina na "crescente inscrição de suas vidas na ordem estatal, oferecendo assim uma nova e mais temível instância ao poder soberano do qual desejariam liberar-se" (AGAMBEN, 2014, p. 127). A estrutura biopolítica legitima a absorção da pessoalidade do sujeito por intermédio do mecanismo político Estatal, fabricando um sujeito apolítico, circunstância essa, que viabiliza a produção de um corpo social inerte e isento de autonomia. Desta maneira, o sujeito enquanto ser individual almeja se enquadrar na totalidade coletiva, com a finalidade de se autoconhecer, assim, a pluralidade de sujeitos se transforma em um corpo social uniforme e homogêneo.

Essa uniformidade é o mecanismo pelo qual o Estado reprime a potencialidade política contida no corpo social, sendo que, o paradigma biopolítico institui à vida natural expressiva capacidade política, gerando uma possível fonte de ameaça à soberania Estatal. Dessa forma, 
visando à manutenção de seu poder, o Estado suprime e se apropria desta disposição, a imergindo e fragmentando em uma pluralidade, submetendo o sujeito a uma existência apenas valorada se em conformidade com a sistematização governamental.

Por isso, para além de tão somente um acontecimento passageiro, com Agamben (2004) pode-se entender o estado de exceção ${ }^{1}$ como a forma de governo dominante na contemporaneidade. O estado de exceção torna-se a regra e, para além de uma forma de organização política, se estrutura como uma forma biopolítica de sujeição, de controle, de produção de sujeitos, de novos espaços e temporalidades.

O estado de exceção não é mais uma medida excepcional, pois, ele se mostra claramente como algo que atualmente é constitutivo da ordem jurídica, pois, passa a ser um mecanismo, uma técnica a serviço do Estado de Direito - no mais das vezes, paradoxalmente para garantir direitos (AGAMBEN, 2004). O estado de exceção aqui, se mostra como parte da regra, como constitutivo da própria regra, pode-se dizer até mesmo, como instituidor da suspensão da regra que confirma o estado de exceção.

Assim, ao mesmo tempo em que os instrumentos normativos são fundados pelas relações entre os sujeitos, eles moldam o ser do sujeito, ou seja, o ente Estatal utiliza esses instrumentos como meio de formar e reger a esfera do corpo social. De acordo com Agamben (2007, p. 34) "existe uma figura-limite da vida, um limiar em que ela está, simultaneamente, dentro e fora do ordenamento jurídico, e este limiar é o lugar da soberania", isto é, o processo de apropriação do sujeito é legitimado por esse ordenamento, que fundamenta e, concomitantemente, fragmenta a sua existência².

Esse sistema disciplinador é centrado "no corpo, produz efeitos individualizantes, manipula o corpo como foco de forças que é preciso tornar úteis e dóceis ao mesmo tempo" (FOUCAULT, 1999a, p. 297). O corpo individual é inserido no processo de inscrição da vida natural ao conjunto político, assim, a partir do controle individual objetiva-se a abrangência da totalidade social, instituindo-se o domínio sobre a coletividade, fomentando a estratégia biopolítica.

A soberania governamental do Estado-nação se potencializa através da vulnerabilidade do seu corpo social, fixa sua legitimidade baseando-se na necessidade de adequação do sujeito enquanto membro da nação, configurando uma espécie de pluralidade contida no sistema de unicidade. Assim, o processo disciplinador é articulado para reger a multiplicidade de corpos individuais que almejam se enquadrar nessa composição estrutural, visando proteção e eliminando, tanto quanto possível, as diferenças internas, fortalecendo uma instituição una.

1 “O estado de exceção separa, pois, a norma de sua aplicação para tornar possível a aplicação. Introduz no direito uma zona de anomia para tornar possível a normatização efetiva do real” (AGAMBEN, 2004, p. 58). A separação entre norma e normatividade, ou seja, entre a norma que é suspensa e a normatividade que é instituída no âmago do estado de exceção, exerce o poder soberano de vida e morte sobre todos, a soberania não tem limites e cria uma ambiência em que os direitos e a condição humana - pelo menos de alguns - está suspensa.

2 A fragmentação do sujeito enquanto ser individual é essencial para a manutenção dessa sistemática de subordinação, já que, propicia o controle e eventual modificação da multiplicidade de sujeitos que formam o corpo social, viabilizando o exercício soberano Estatal, ordenando uma estratégia de extinção e expansão da estrutura instituída, legitimando um arranjo segregatório na conjuntura interna. Contudo, essa segmentação institucionaliza o isolamento e, simultaneamente, fortalece o vínculo entre o corpo subordinado, tornando essa multiplicidade unitária o objeto central do mecanismo disciplinador Estatal. 
Entretanto, Foucault (1999a) observa que a disciplina do corpo individual não propicia o domínio sobre a totalidade do corpo social, que só é possível por intermédio do biopoder, que sistematiza o enquadramento biopolítico, apropriando-se da vida natural em todas as suas esferas, tanto de produção quanto reprodução, ou seja, absorve todas as questões relacionais sociais. Assim, toda a multiplicidade humana é abrangida, gerando um processo de reformulação da vida natural, em que a coletividade é administrada em sua integralidade.

Dessa forma, têm-se duas diferentes técnicas de governo e dominação, em que "uma figura não abole a outra; trata-se antes de uma modificação e de um novo ajustamento nas engrenagens do poder-saber" (GIACOIA JUNIOR, 2004, p. 10). Pode-se dizer que independentemente da forma de poder exercida pelo ente soberano, seja ela a técnica disciplinar ou por intermédio do biopoder, o objeto de dominação continua o mesmo, segue-se a estratégia de absorção da vida natural pelo corpo político Estatal.

No entanto, salienta-se que as técnicas de governo apresentam diferentes formas de se apropriar desse objeto; a tecnologia do biopoder não pode ser considerada disciplinar porque não se dirige aos corpos individuais, como o fazem as disciplinas. O biopoder apropria-se da espécie, do ser humano como ser vivo, da vida em seu aspecto natural e/ou político. Assim, o biopoder intervém para controlar, normatizar e regulamentar a capacidade de produção do sujeito na esfera coletiva (GIACOIA JUNIOR, 2004).

Sendo a disciplina do corpo unitário e a regulamentação da totalidade do corpo social dois diferentes mecanismos de controle governamental, ambas as formas de dominação são aderidas como forma de reger o poder sobre a vida, ou seja, elas não se anulam, se somam, ordenando uma sistemática em que o corpo individual é enquadrado na composição coletiva, e a pessoalidade do sujeito é dominada e fixada em sociedade. Assim, a manutenção do poder soberano Estatal se dá por uma estratégia em que a individualidade é absorvida pela coletividade e, a coletividade é atomizada em uma unicidade.

Desse modo, a vida natural se torna campo da decisão soberana, em que a imposição da biopolítica se faz por meio do exercício do poder normalizador, pela instituição de padrões de inclusão e exclusão de indivíduos e grupos nos processos de socialização e politização, que também incidem sobre as forças do corpo. "Todo esse grande agenciamento incluía tanto o corpo global da população como os corpos dos indivíduos, na forma de um bio-poder" (GIACOIA JUNIOR, 2004, p. 12), em que se tem o controle sobre a vida e a regulamentação do conjunto.

Nesse contexto, a instituição biopolítica condiciona a um exercício governamental baseado na integralidade do corpo social, não mais apenas no indivíduo em si, pois ao se atomizar essa individualidade, fomenta-se a existência de uma pluralidade desobrigada de uma existência ativa, legitimando um sistema hierárquico que determina as aspirações internas. Logo, tem-se uma existência passiva, em que o soberano impõe "a força natural de um único interesse comum e de uma opinião unânime" (ARENDT, 2017a, p. 49).

A inserção da vida natural no corpo político do Estado (biopolítica) gera um pacto social em que a soberania é tida como expressão da vontade geral e, legitima o poder soberano Estatal, 
institucionalizando a ficção de unicidade entre ente soberano e corpo subordinado. A constituição de uma estrutura homogênea é essencial para a manutenção da soberania Estatal, pois, desta forma, as heterogeneidades internas serão regidas e anuladas pela imposição de práticas políticas enraizadas na habitualidade social-estrutural.

Uma das características essenciais da biopolítica é a redefinição contínua da vida, que se transforma em uma linha em movimento que deve ser redesenhada (AGAMBEN, 2014). No entanto, essa redefinição da vida não ocorre em respeito à sua particularidade e evolução, mas sim, para sempre a manter adequada ao enquadramento favorável à soberania, ou seja, não pretende controlar o sujeito isoladamente considerado, mas sim, se preocupa em regular o equilíbrio das relações do sujeito enquanto ser coletivo.

Para manter a estrutura unitária estatal, impõe-se um único e comum objetivo, fomentando a individualização das multiplicidades, visando à conservação do status quo, em que o corpo social se submete ao domínio estatalista almejando qualificar-se como povo soberano. Essa unificação aniquila a particularidade do sujeito, que ao se enquadrar ao conjunto estrutural, rejeita a figura do "outro", do diferente, ou seja, necessita se reconhecer enquanto semelhante para se autoaceitar, potencializando as barreiras para inclusão ao corpo polítco-social Estatal.

Por conseguinte, a expressão do poder biopolítico reside em o Estado se apoderar do sujeito, de tal maneira, que sua existência se encontra valorada apenas se em conformidade com os requisitos necessários ao enquadramento enquanto sujeito-cidadão, ou seja, desta forma, o ente Estatal decide o corpo legítimo de proteção e de garantia de direitos, privatizando o acesso a sua delimitação territorial, assegurando o controle sobre seu corpo social, restringindo o seu agir de forma autônoma.

Desse modo, o enquadramento biopolítico, no arranjo nacionalista Estatal, objetiva anular qualquer possibilidade de interferência externa sob o domínio de seu território, isolando o sujeito do mundo e o enquadrando em suas fronteiras, legitimando uma sistemática política de segurança, que dispõe de uma "atitude ativa e construtiva, tanto dentro quanto fora das fronteiras nacionais: da preservação da atual ordem social e política interna" (HARDT; NEGRI, 2005, p. 43), ou seja, esse enquadramento fomenta a estratégia de necessidade de proteção territorial.

Assim, transcende-se o mecanismo disciplinador baseado apenas na obediência, instigando na esfera social a sensação de incerteza e insegurança, legitimando a necessidade de proteção oriunda de um ente soberano. O Estado, ao se autoinstituir perante o corpo social, o concebe como um produto de perpetuação de seu controle, utilizando suas forças como forma de expansão, visando a ampliação da legitimidade de seu domínio, estabelecendo uma estratégia regulamentadora que institui a sistematização do medo.

Essa sistemática do medo institucionalizado, frente ao cenário biopolítico nacionalista, delimita e ao mesmo tempo possibilita o exercício da soberania Estatal, já que, o processo de homogeneização necessita da existência de heterogeneidades, para que o soberano institua o discurso separatista, fomentando a ideia de instabilidade interna. Ao difundir esse sentimento de insegurança, a constituição do Estado é propagada como sendo imprescindível à defesa dos 
interesses do corpo social.

Por conseguinte, o espaço territorial deve representar a figura de um local seguro, que ofereça proteção às ameaças e causas de desequilíbrio interno que o exterior simboliza, reafirmandose como fonte segura à nação, suscitando um cenário hostil e de recusa às diversidades. Assim, o poder soberano Estatal se consolida ao basear-se nas demandas de seu corpo social, por isso, o Estado é eficaz, mas não eficiente, visando a manutenção do seu objeto de dominação e controle de seu exercício governamental.

Essas circunstâncias, no cenário nacionalista, ordenam o controle de uma multiplicidade determinável de sujeitos, abrangendo tanto o seu corpo social, parcela integrante do arranjo político de sua delimitação territorial, quanto a parte privada dessas prerrogativas, "o outro", que não pertence a estrutura Estatal nacional. Dessa forma, o Estado controla as manifestações que ocorrem em suas fronteiras, sejam elas do seu corpo social interno ou do conjunto excedente, que está fora desse limite territorial.

Concomitantemente com a capacidade de produzir o ser social, o ente Estatal dispõe o direito de destruir o mesmo, através de uma estratégia em que se interioriza a ideia de ameaça pela conjuntura externa, em que a estrutura e direitos internos estariam comprometidos. Dessa forma, legitima-se o corpo social a defender o Estado, ou seja, o ente estatal pode dispor do seu próprio corpo social, para manter a sua estrutura, exercendo indiretamente o poder sobre a vida e a morte, sendo lícito lhe expor a vida e, principalmente, escolher qual vida estará sujeita a esse enquadramento (AGAMBEN, 2014).

No entanto, ainda que o Estado detenha a maior força disponível em sociedade, ele não existe em si, para exercer seu poder soberano necessita formar e moldar um corpo social subordinado, e ao fazê-lo por intermédio do biopoder, obrigatoriamente classifica o corpo excedente como uma vida passível de eliminação, fomentando uma sistemática hegemônica, que fortalece o arranjo biológico-político interno, instituindo a ideia de autossuficiência, visando consolidar sua vinculação com seu corpo social.

Forma-se e exige-se um padrão de aceitabilidade, tanto para pertencer ao corpo social, quanto para ser excluído dele, ou seja, essa estratégia de fortalecer o biológico domina o corpo social através de um processo em que se institucionaliza um arranjo autocentrado, rejeitando e hostilizando as diversidades; ainda, o Estado institui e materializa sua soberania categorizando a vida natural, por intermédio de um processo que ordena a "simultânea possibilidade de autorizar a vida e de autorizar seu holocausto" (AGAMBEN, 2014, p. 11).

Esse poder sobre a vida estabelece um procedimento de sujeição centrado na legitimação dos seus mecanismos de controle, sendo essencial para dominar o corpo subordinado, pois concretiza sua vinculação através de uma estratégia em que visa manter seu poder baseado no medo, pois assim, o corpo social almeja se enquadrar em sua estrutura objetivando estabilidade, e para tanto, cede à manipulação, rejeita o outro a fim de reafirmar sua pertença. Nessa sistemática, o corpo social deve sentir medo e, simultaneamente, sentir-se seguro e se autoconhecer na figura estatal, ainda que não de forma natural. 
"Encarado nestes termos, o direito de vida e morte já não é um privilégio absoluto: é condicionado à defesa do soberano e à sua sobrevivência enquanto tal" (FOUCAULT, 1999b, p. 12), ou seja, o poder sobre a vida não é uma forma absoluta de manutenção da soberania, entretanto, é a forma histórico-política de mais fácil adequação, já que, o poder soberano evolui, mas não na mesma medida que o conjunto social. Assim, quando a soberania está em crise, através do biopoder, é fácil manter o controle, baseando-se nas vulnerabilidades e individualidades do corpo social, instigando uma hostilidade às diferenças.

Essa hostilização às diversidades fomenta uma governabilidade em que a figura do migrante é concebida como objeto do plano governamental, pois representa a vida abjeta, que ocupa um espaço que não the pertence, ameaçando a estabilidade interna, ou seja, simboliza a vida que o Estado está autorizado a eliminar a fim de atestar seu poder. Assim, o fluxo migratório evidencia a limitação estatal em reger a esfera político-social-jurídica, gerando uma lacuna social, em que a dignidade humana e demais direitos e garantias, têm como preceito o paradigma da pertença, não mais a percepção de semelhança humana.

\section{O REPENSAR DO ESTADO A PARTIR DA ABERTURA AOS (PELOS) DIREITOS HUMANOS COMO FORMA DE RECONHECIMENTO DO MIGRANTE COMO SUJEITO DE DIREITOS}

Nesse passo, a sujeição do pertencer ao espaço público de privação obstaculiza a compreensão do migrante como sujeito de direitos, tendo em vista, o cenário nacionalista, em que o vínculo do nacional com o Estado o transforma em cidadão e o legitima a gozar de toda a proteção dos instrumentos jurídicos, assim, ao migrante resta à lacuna do sistema jurídico-político que o aniquila e o reduz a vida nua. No sistema do Estado-nação, a aplicação dos Direitos Humanos encontra-se vinculada ao enquadramento biopolítico, em que o Estado decide o corpo legítimo de proteção e também o excluído de tal garantia.

O conceito de vida nua ganha contornos importantíssimos para entender-se a situação contemporânea. O traçado desse conceito para o autor, se inicia com a distinção entre zoé e bíos, onde a primeira é não mais que a vida natural que qualquer ser vivente desfruta e, a segunda é uma forma de vida que pode ser qualificada podendo adentrar à esfera da política e por isso o termo bíos politicós aristotélico (AGAMBEN, 2014). Nessa maré, zoé é uma vida desqualificada, uma vida que não se encontra adstrita à política, é uma vida não politizada. É a vida nua em seu estado bruto, e a produção dessa vida nua se dá exatamente pela não inserção dela na vida política. O "homem nu" está marcado por um limiar de indistinção entre poder viver e dever morrer, pois, a sua vida nua não tem significado para além da possibilidade latente de morte³.

\footnotetext{
3 Agamben aqui nos remete à tradição grega para tratar de zoé e bíos, onde zoé exprime a vida de qualquer ser natural, ou seja, uma vida desqualificada de qualquer predicado para além de ser simplesmente vivida, trata-se de uma vida comum a todos os seres vivos, seja aos homens, animais ou deuses, e bios, indica "a forma ou maneira própria de um indivíduo ou de um grupo" (AGAMBEN, 2014, p. 9). Nesse sentido, não se tinha a noção de que a simples zoé, ou seja, o simples ato de viver era um privilégio, mas sim, centrava-se o privilégio da vida no viver politicamente. Na filosofia política de Giorgio Agamben, a zoé aparece intrinsecamente ligada à vida nua, há uma vida desqualificada
} 
Para Agamben (2014), a (produção da) vida nua é o centro do projeto biopolítico da modernidade que é exacerbado pela experiência nazista no interior do campo. "A implicação da vida nua na esfera política constitui o núcleo originário - ainda que encoberto - do poder soberano" (AGAMBEN, 2014, p. 14). E o poder soberano, se manifesta de maneira mais bem acabada na forma do estado de exceção que tem como sua repercussão mais evidente o espaçotempo - a-espacial e atemporal - do campo.

Quando o sujeito perde o seu status político, ele perde todas as qualidades que possibilitam aos outros tratá-lo como semelhante (ARENDT, 2017b), dessa forma, a angústia do migrante não decorre do fato de ele ser privado da vida, da liberdade, nem da igualdade perante a lei ou da liberdade de opinião, mas do fato de já não pertencer a qualquer comunidade, de ter sua existência e humanidade invisibilizadas. Assim, a figura do migrante representa um sujeito que existe, mas não possui as características para tal, criando um não sujeito.

Por conseguinte, o migrante é isolado do mundo e enquadrado nas fronteiras do Estadonação, fomentando-se uma violência velada que decorre da sua impossibilidade de ação, em razão de o Estado impor as condições para o reconhecimento ou não do sujeito, restringindo e legitimando quem tem direito ao direito, ou seja, o Estado detém em si os mecanismos de mobilização, o que reduz a capacidade de agir do migrante, o condicionando a necessitar do que lhe é negado, ou seja, a pertença lhe é oferecida, entretanto, de forma inacessível.

Dessa forma, o controle biopolítico age "como uma figura de separação e sequestro da vida no campo de decisão da soberania, conservando a memória da exclusão-includente que constitui assim a dimensão originária da política" (GIACOIA JUNIOR, 2008a, p. 39). Consequentemente, o direito reflete uma espécie de relação contratual entre soberano e corpo subordinado, ao invés de ser concretizado como um dos deveres do Estado, ou seja, o ente estatal se apropria de um objeto das relações sociais e o impõe como mecanismo de manutenção da sua soberania.

Nesse contexto, os Direitos Humanos passaram a ser aplicados somente sob a forma de direitos nacionais, e o próprio Estado passou a garantir ao sujeito, enquanto cidadão, esses direitos, ou seja, a figura da cidadania representa uma alma nacional, e sua própria existência está acima da lei. "Desde o momento em que os Direitos Humanos propriamente ditos se afirmaram e ganharam força política, tornaram-se também íntimos do Estado" (FERREIRA, 2009, p. 147), evidenciando que os Direitos Humanos estão vinculados ao Estado soberano, não ao sujeito.

Constatada a inseparabilidade dos Direitos Humanos da soberania Estatal, percebe-se sua condição de elemento constitutivo estrutural, sendo um dos fundamentos da instituição do corpo político social, baseando-se em uma estratégia reducionista, em que se institucionaliza a sua violação, não apenas de forma ativa, mas também em forma omissiva, interferindo diretamente na

que, para além de permitir-se o viver, pode atribuir-lhe a morte. A produção da vida nua no texto agambeniano é a produção indistinta da zoé, é o que se produziu no campo e é o que se produz atualmente no estado de guerra global. "O vivente possui o lógos tolhendo e conservando nele a própria voz, assim como ele habita a pólis deixando excluir dela a própria vida nua. A política se apresenta então como a estrutura, em sentido próprio fundamental, da metafísica ocidental, enquanto ocupa o limiar em que se realiza a articulação entre o ser vivente e o lógos. A "politização" na vida nua é a tarefa metafísica por excelência, na qual se decide da humanidade do vivente homem, e, assumindo esta tarefa, a modernidade não faz mais do que declarar a própria fidelidade à estrutura essencial da tradição metafísica. A dupla categorial fundamental da política ocidental não é aquela amigo-inimigo, mas vida nua-existência política, zoé-bios, exclusão inclusão" (AGAMBEN, 2014, p. 15). 
recepção do migrante, estabelecendo o nexo entre lei e vida, instituindo a necessidade de associação política para poder usufruir de tais garantias.

Desta maneira, o Estado condiciona o migrante a um cenário em que ele representa uma minoria que ocupa um espaço que não é seu, e não é passível de recepção, concebendo o seu direito de participação de forma hostil, no sentido em que lhe é privada a possibilidade de manifestação coletiva e política, pois a igualdade em direito não é dada, mas instituída a partir da constituição do corpo social. Assim, o sujeito é subordinado à adequação ao sistema do ente Estatal, que se baseia no processo de produção, ignorando a complexidade das relações políticas e a gama de diversidades trazidas pelos fluxos migratórios.

A formatação dos Direitos Humanos no arranjo nacionalista Estatal legitima a manutenção da hostilidade no exercício de sua governabilidade, aniquilando o reconhecimento do sujeito perante os instrumentos jurídicos. Dessa forma, o sujeito não está subordino ao Estado devido à força bruta, mas sim, pela necessidade de ter sua existência enquanto sujeito de direitos reconhecida, sendo que, tal garantia é assegurada aos cidadãos, não à pessoa humana, ou seja, o migrante é o limite entre o ser e o não-ser social (REDIN, 2010).

Por conseguinte, o migrante representa a lacuna entre ser humano e cidadão, uma vez que, sua figura é a materialização da discricionariedade do ente Estatal no processo de humanização do sujeito, ou seja, é o mecanismo pelo qual se justifica a vinculação ou abandono do outro, evidenciando a desvinculação entre o humano e a proteção jurídico-política, sendo a valoração da vida baseada nos limites das fronteiras do Estado soberano, quantificando e criando um ideal de humanidade.

Se o modelo do campo no nazismo levou a consequências nunca antes vivenciadas pela história, ou seja, o projeto biopolítico ancorado no aparato de biopoder que negava a vida para protegê-la, a negação da vida no judeu é a mesma negação da vida no migrante, terrorista, no outro que é inimigo do Estado, e, que pode ser todo e qualquer um, mas essa negação é justamente para conservar a vida provocando terapeuticamente a morte (ESPOSITO, 2010). Esposito (2010) refere a biopolítica nazista, e a biopolítica como um todo, como um controle biológico da população que no caso específico na biopolítica nazista deve ser vista como um controle biológico eugênico da população.

Eis a união entre o campo e a biopolítica eugênica que resultam no paradigma imunitário ${ }^{4}$

4 A noção de imunização ou de paradigma imunitário trazida por Esposito repousa sobre ser a imunidade para o autor um conceito ao mesmo tempo político e biomédico, nesse sentido, no âmbito biomédico é a imunidade uma condição "imposta" ao sujeito seja natural ou induzida que o coloca imune à determinada doença, enquanto, jurídico-politicamente trata-se de uma isenção temporária ou definitiva concedida ao sujeito pelo ordenamento jurídico-político em relação à determinadas obrigações ou responsabilidades ou seja, nessa noção de imunidade bios e nomos se relacionam, vida e política comunicam-se. No entanto, este relacionar-se não se dá por sobreposição ou justaposição, como bem refere Esposito (2010, p. 74) "no paradigma imunitário, bios e nomos, vida e política, resultam ser os dois componentes de um único, incindível, conjunto que só adquire sentido a partir da relação entre eles. A imunidade não é apenas a relação que liga a vida ao poder, mas o poder de conservação da vida". Esposito prossegue a sua construção acerca do paradigma imunitário afirmando que nele, há uma articulação para além da dualidade biopolítica, ou seja, para além de uma percepção de que o paradigma biopolítico - e o paradigma imunitário é um paradigma biopolítico - se mostra em uma dualidade positivo/negativo em que a vida ou é promovida ou é extirpada, num limiar entre proteger ou excluir, entre negar a vida ou promovê-la, entre violência e proteção. No paradigma biopolítico imunitário como construído por Esposito há uma articulação entre negativo e positivo que 
construído por Roberto Esposito, numa tríade que para o autor constitui a modernidade e rompe com a biopolítica enquanto mera mediação entre bios e nomos, mas, sim, coloca a biopolítica como um paradigma de produção da vida e da morte que medeia as relações político-sociais da modernidade em diante. Esposito (2010) vê na sanha imunitária a peça chave para suprir as lacunas deixadas por Foucault na sua biopolítica, pois, para o autor a imunização constitui de maneira central a forma com o que o Estado se movimenta na garantia da soberania e na ação soberana.

Nesse cenário, a “igualdade e liberdade são ficções ideológicas que pertencem ao Estado, embora a realidade que sustentam seja de uma sociedade e existência diária de exploração, opressão e individualismo" (DOUZINAS, 2009, p. 172). A restrição de igualdade resulta na supressão de liberdade, tendo em vista que, o sujeito só se torna livre por meio da ação política, ou seja, constrói politicamente a sua existência, instituindo demandas que visam ampliar o seu espaço de ação.

Essa restrição de igualdade decorre, paradoxalmente, do desejo por unidade, que resulta em uma necessária forma de associação, que então, é utilizada como meio de exclusão. A lei institui a possibilidade de os sujeitos formarem um espaço público comum, em que a igualdade é normatizada, entretanto, derivando não da natureza humana, mas de uma convenção artificial, em que o Estado modela o corpo social a sua própria imagem, por intermédio dos instrumentos jurídicos. Desta maneira, o nacional recusa o migrante, objetivando não se associar ao outro, ao diferente, a fim de atingir sua máxima igualitária, negando acesso à participação política e social, ou seja, não lhe resta nenhuma instituição que os ampare, o que ordena a condição de vulnerabilidade do sujeito sem vínculo político com o Estado-nação.

Tem-se, então, um empecilho no que concerne a aplicação dos Direitos Humanos, pois, esses deveriam ser inerentes à pessoa humana, entretanto, o ente Estatal os utiliza como objeto direto de seu poder, evidenciando que a igualdade humana é apenas uma igualdade de direitos, ou seja, é uma igualdade de objetivo humano, moldada sob o prisma da soberania Estatal. A humanidade, ao contrário do ser humano, é uma, mas ao mesmo tempo diversa, é uma pluralidade unitária, que em certo contexto, foi convertida pela política, assim, o humanitário corresponde não apenas ao que concerne sua singularidade, mas também em benefício estatal. Este esvaziamento do humano é ordenado por um esquema normativo, que estabelece os parâmetros de aceitabilidade ao espaço Estatal, sendo que, a perda desse acesso é o que justifica a exclusão do migrante do corpo social, ou seja, o território se sobrepõe a concepção universalista dos Direitos Humanos.

Nesse ponto, o Estado-nação opera reforçando a vida natural, "discriminando em seu interior uma vida por assim dizer autêntica e uma vida nua privada de todo valor político $\square$ (AGAMBEN, 2007, p. 139). Com isso, evidencia-se que para além das fronteiras, resta apenas a privação de espaços e de direitos, não há possibilidade de manifestação política ou social, mas sim, apenas controle do ser, pondo em questão a constituição, funções e categorias fundamentais que estruturam o paradigma estatal, que ao absorver o ordenamento jurídico para si, depara-se com capacita a vida a partir da forma imunitária (ESPOSITO, 2010). "Isto significa que a negação não é uma forma de sujeição violenta que de fora o poder impõe à vida, mas o modo intrinsecamente antinômico em que a vida se conserva através do poder. Deste ponto de vista pode bem dizer-se que a imunização é uma protecção negativa da vida. Ela salva, assegura, conserva o organismo, individual ou colectivo, a que é inerente - mas não de uma maneira directa, imediata, fronta; submetendo-o, pelo contrário, a uma condição que ao mesmo tempo lhe nega, ou reduz, a força expansiva" (ESPOSITO, 2010, p. 74). 
sua limitação enquanto garantidor e promotor de direitos, devido ao fato de a formação do sujeitocidadão ter como requisito a nacionalidade.

A estrutura biopolítica Estatal institui a vinculação entre sujeito e Estado, mecanizando a vida natural, a transformando em um elemento de sua constituição, a inserindo em um espaço de inclusão/exclusão, em que subordina o sujeito, e a única forma de integração é por meio da sujeição. Diante desse cenário, o sujeito foi despido de sua humanidade, ou seja, é reconhecido enquanto tal apenas a partir de sua submissão ao enquadramento estrutural, que por sua vez, o torna objeto, obstaculizando a abrangência dos Direitos Humanos.

Por isso, o fato de ser pessoa humana não garante percepção de semelhança, em um cenário político em que há privação do acesso ao espaço público, devido ao modelo tradicional de Estadonação, que institucionalizou o medo do outro. Ao desvincular o indivíduo na nação, as garantias humanas baseadas na suposta existência do ser humano em si, desmoronaram no momento em que se confrontou com seres que haviam perdido todas as outras qualidades e relações específicas, exceto que ainda eram humanos (ARENDT, 2017b).

Dessa maneira, o direito aos Direitos Humanos independe do reconhecimento Estatal, pois é inerente a condição humana, entretanto, quando aplicados pelo Estado, condicionam o sujeito a um enquadramento estrutural, caso contrário, lhe é restringido o acesso a tal garantia, ou seja, o cenário de recepção ao migrante lhe impõe uma impolítica vida natural, evidenciando que em meio à diversidade trazida pela mobilidade humana, a caracterização plural dos Direitos Humanos é imprescindível.

Quando fora do Estado de origem, o sujeito torna-se uma mera vida impolítica, que tem sua condição humana invisibilizada, e consequentemente perde o acesso aos seus direitos, em uma estrutura em que o Estado molda os instrumentos jurídicos a sua própria imagem. Desta forma, evidencia-se que o caráter universal dos Direitos Humanos é fundamental para o reconhecimento do outro enquanto sujeito, para a construção e manutenção de uma sociedade comunitária, baseada no internacionalismo ${ }^{5}$, superando a imposição das fronteiras.

No momento em que se contrapõe mobilidade humana e fronteiras, percebe-se que o corpo político-social e o ordenamento jurídico não são de ordem natural, mas sim, produtos do Estado e do direito, que agem como redutores da ação plural humana, e visando a manutenção dessa estrutura, o Estado é o único ente que possui legitimidade para agir com violência. Para tanto, atomiza o sujeito, fazendo com que o nacional sinta-se lesado pela presença do migrante e, simultaneamente, valorizado em relação a ele, fomentando um mecanismo incompatível com os fundamentos dos Direitos Humanos.

Assim, a concretização da universalidade dos Direitos Humanos vê-se desafiada ao ter que responder a nação, que objetiva restringir o ingresso do migrante, defendendo uma posição de fechamento das fronteiras, e ao mesmo tempo dar conta de uma agenda que impede tamanha discriminação de acesso (LUCAS; SANTOS, 2016). Tem-se assim, uma ambiguidade originada

\footnotetext{
$5 \mathrm{O}$ termo internacionalista expressa o ideal de um mundo sem a divisão de fronteiras, e sem hierarquização em qualquer esfera, retrata a máxima igualitária humana, "com caráter universalista e humanista” (LÖWY, 1998, p. 2).
} 
pelos instrumentos jurídicos, pois ao mesmo tempo em que garantem proteção ao nacional excluem o migrante, ou seja, ao nacional configura-se o Estado de Direito, enquanto ao migrante o Estado de Exceção.

Os Direitos Humanos pressupõem acessos e escolhas, que ao mesmo tempo demandam e possibilitam a participação do sujeito em espaço público, ou seja, é um ciclo inviável, pois quem o demanda não tem acesso, e sem acesso não é legitimado a demandar. Tendo em vista que a pluralidade humana é anterior à constituição Estatal, percebe-se que essa exclusão é uma técnica de governo, que a subordina e a anula, a transformando de regra em exceção, não comportando a complexidade de relações e demandas dos fluxos migratórios, não por falta de opção, mas por estratégia de governabilidade.

A universalidade dos Direitos Humanos, conduzida pela estratégia nacionalista, não comporta o avanço da mobilidade humana e a gama de diversidade que ela carrega consigo, fazendo-se necessária a criação de um arranjo jurídico-Estatal inclusivo, que permita considerar a diversidade como elemento essencial humano (LUCAS; SANTOS, 2016). O direito é objeto das relações sociais, por isso, as formas relacionais interferem diretamente em sua criação e aplicação, dessa forma, paradoxalmente, o mesmo direito que é instrumento de exclusão, pode ser de inclusão.

Os direitos humanos "embora fossem apresentados como absolutos, eles são instrumentos limitados e limitadores do Direito; embora fossem concebidos acima da política, eles são o produto da política do seu tempo" (DOUZINAS, 2009, p. 175). Visto que, os Direitos Humanos são inerentes à condição humana, mas sua aplicação depende da estrutura Estatal, pode-se dizer que a existência do ser humano se dá a partir da sua construção política, pois a mera vida natural representa a vida passível de exclusão, sem valor algum, que o Estado e seus integrantes estão autorizados a eliminar.

Assim, o direito de ser reconhecido enquanto sujeito está vinculado ao acesso ao espaço público, ou seja, ao pertencimento nacional, já que, a demanda por participação social ativa, ocorre no interior das fronteiras, por isso, ainda que a recepção dos migrantes seja tratada em torno dos Direitos Humanos, fica evidenciada a limitação estatal no que tange sua proteção territorial, evidenciando a precariedade e insuficiência desse sistema, porque se reduz as implicações da mobilidade humana ao interesse nacional.

Por isso, faz-se necessária a desvinculação entre ordenamento jurídico e o princípio da soberania, visando à instituição de "um direito não estatal, amparado numa insólita cidadania internacional fundada nos abusos do poder e na condição infeliz das vítimas desse abuso, quaisquer que sejam" (GIACOIA JUNIOR, 2008b, p. 303). Dessa forma, o fluxo migratório fomenta a necessidade da concretização da função emancipatória dos Direitos Humanos, superando as barreiras fronteiriças.

Nesse contexto, o migrante rompe a seguridade das fronteiras, desafia a imposição fixa e autocentrada da constituição Estatal, por isso, o direito de migrar é um "direito humano de ação política dentro do espaço público" (REDIN, 2010, p. 186). Assim, sociologicamente e historicamente, o desafio da humanidade é desconstruir a ideia institucionalizada de individualidade, 
para que assim, seja possível construir uma humanidade baseada na hospitalidade, em que as diversidades possam ser respeitadas e comunicadas.

Kant ressalvou que o direito a hospitalidade significa o direito a não ser tratado com hostilidade, devido ao fato de ninguém ter mais direito do que o outro a estar em um determinado lugar da Terra, por isso, as partes podem entre si estabelecer relações pacíficas, podendo assim aproximar cada vez mais o gênero humano de uma constituição internacionalista, em que o ser humano tenha valor em si, superando as delimitações fronteiriças, reconhecendo que o mundo é de todos (KANT, 1995).

Assim, acredita-se que a universalidade dos Direitos Humanos tem a função de tornar o mundo um lugar de acessos, que comporte a pluralidade das relações humanas, que transcenda a imposição de identidade política baseada no pertencimento, construindo uma noção de humanidade baseada na participação para além das fronteiras. Para a concretização destes direitos, faz-se necessário repensar a função e estrutura do Estado-nação, ordenando a constituição de um espaço internacionalista, em que as relações de poder não suprimam a humanidade do sujeito.

\section{CONCLUSÃO}

Refletir sobre as questões suscitadas acerca do reconhecimento do outro enquanto sujeito de direitos frente ao fenômeno migratório, e a concretização da universalidade dos Direitos Humanos, exige que se questione a constituição e estruturação Estatal, tendo em vista que, é no limite de suas fronteiras que essas relações ocorrem.

A estrutura Estatal nacionalista permite reduzir a pluralidade e complexidade das relações humanas, categorizando a vida natural, e a enquadrando ao paradigma biopolítico, que ao politizar a vida, transforma o sujeito em um produto da soberania Estatal, impondo a influência política em toda e qualquer relação humana.

Nesse contexto, pode-se dizer que a vida humana é um produto político, independentemente da vontade do sujeito, pois suas ações e omissões são ordenadas pelo aparelho Estatal. Por conseguinte, a estratégia nacionalista não constitui apenas a estruturação do Estado, mas também fabrica o sujeito, influenciando diretamente suas formas relacionais.

Assim, tem-se a figura de um sujeito territorializado, isolado no interior das fronteiras do Estado, por isso, a soberania Estatal origina-se e se mantém através da unificação de seu corpo social, e o ordenamento jurídico legitima a violação de garantias ao sujeito não pertencente a esse corpo, fomentando a figura do "outro", em um cenário de hostilização às diferenças.

O combate à diversidade é institucionalizado porque o outro representa causa de instabilidade interna, ou seja, o diferente ameaça a estrutura Estatal, é ela que se apresenta vulnerável, entretanto, persuade seu corpo social, e o faz acreditar que a vulnerabilidade lhe pertence, e que o meio eficaz de proteção é a partir da manutenção de sua soberania.

Por isso, o corpo social ao mesmo tempo em que assegura a estrutura Estatal, detém a capacidade de modificá-la, contanto que utilize toda a sua potencialidade política em benefício 
próprio, superando sua visão vulnerável de si, percebendo que é ele que cria o poder soberano, logo, é ele que detém a maior capacidade política no conjunto Estatal.

Entretanto, o fato é que o Estado vinculou o sujeito de tal maneira a si, que ele apenas valora sua própria existência se em conformidade com a constituição Estatal. Dessa forma, o corpo social concebe as aspirações do ente governamental como se suas fossem, entendendo-se como parte ativa da instituição Estatal, não por sua capacidade política, mas pela sua subordinação e "fidelidade".

Diante desse cenário de domínio do ente Estatal sobre o corpo social, é que os instrumentos jurídicos são sistematizados, ou seja, são moldados por uma ótica unitária, influenciada diretamente pelo Estado-nação, por isso, ainda que sejam objeto das relações e demandas sociais, se transformam em um produto da soberania Estatal, incorporados à estratégia de proteção do interesse nacional.

Assim, o direito figura como objeto regulador das relações humanas, e se tratando de fluxo migratório, a lacuna jurídico-social institui um cenário em que o migrante é incluído pelos instrumentos jurídicos, para definitivamente ser excluído, ou seja, sua exclusão é sua forma de inclusão. Dessa forma, o ordenamento jurídico e o enquadramento biopolítico são os meios pelos quais o Estado atinge o ápice do poder.

No contexto nacionalista, a função da biopolítica é fomentar o paradigma da pertença, fabricando uma nação que baste em si, fazendo com que ela rejeite o diferente, tendo na figura do migrante uma existência excedente, que ocupa um espaço que não é seu, por isso, o corpo social e os instrumentos jurídicos são autorizados a lhe excluir.

Consequentemente, tamanha hostilidade faz com que o migrante não tenha acesso fático ao espaço Estatal, ou seja, lhe é privada a esfera político-social, pois o Estado molda o seu espaço para atomizar o sujeito, e assim, manipular as condutas de seus subordinados, para mantê-las favoráveis aos seus interesses.

Diante desse cenário, o ordenamento jurídico institucionaliza a sistemática governamental restritiva, ou seja, o Estado é legitimado a restringir os movimentos migratórios e a isentar-se de sua função de garantidor e promotor de direitos. Ainda, ao incorporar a estratégia biopolítica, o Estado desvincula o migrante de sua existência política, justificando as violações de Direitos Humanos.

Por isso, atingir todos os povos e nações não é suficiente, a universalidade dos Direitos Humanos deve abranger toda a pessoa humana, superando o vínculo com a estrutura Estatal, ainda que ela seja responsável pela sua forma positivada, pois quem lhe dá origem e função, é o sujeito considerado em si.

Tendo em vista que, a mobilidade humana é de ordem natural, pois, desde que se tem conhecimento da existência da humanidade, se tem dela; e a constituição Estatal ocorreu de forma artificial e posterior, é o Estado que tem que se adaptar ao fluxo migratório, não o contrário. Dessa forma, migrar é um ato político, é fazer (re)pensar a estrutura social, política, jurídica e principalmente humana.

Portanto, para a concretização da universalidade dos Direitos Humanos e a compreensão 
do migrante como sujeito de direitos, é fundamental a redefinição das funções do Estado, visando uma constituição desterritorializante, em que a soberania Estatal seja exercida de forma internacionalista, que o sujeito possa pertencer a ela e ao mesmo tempo ao mundo, respeitando a pluralidade humana.

\section{REFERÊNCIAS}

AGAMBEN, Giorgio. Estado de exceção. São Paulo: Boitempo, 2004.

AGAMBEN, Giorgio. Homo Sacer: o poder soberano e a vida nua I. Belo Horizonte: Editora UFMG, 2014.

ARENDT, Hannah. A condição humana. Rio de Janeiro: Forense Universitária, 2017a.

ARENDT, Hannah. O que é política? Rio de Janeiro: Bertrand Brasil, 2002.

ARENDT, Hannah. Origens do totalitarismo. São Paulo: Companhia das Letras, 2017 b.

BOLZAN DE MORAIS, José Luis. As crises do Estado e da Constituição e a transformação espaço-temporal dos direitos humanos. Porto Alegre: Livraria do Advogado, 2011.

DOUZINAS, Costas. O fim dos direitos humanos. São Leopoldo: Unisinos, 2009.

ESPOSITO, Roberto. Bios: biopolítica e filosofia. Lisboa: Edições 70, 2010.

FERREIRA, Carlos Enrique Ruiz. Direitos humanos e soberania: o projeto universalcosmopolita versus o Estado-emuralhado-nacional. 2009. Tese (Doutorado em Ciência Política) - Universidade de São Paulo, São Paulo, 2009.

FOUCAULT, Michel. Em defesa da sociedade: curso no Collège de France (1975-1976). São Paulo: Martins Fontes, 1999a.

FOUCAULT, Michel. História da sexualidade I: a vontade de saber. Rio de Janeiro: Edições Graal, 1999b.

FOUCAULT, Michel. Nascimento da Biopolítica: curso dado no Collège de France (19781979). São Paulo: Martins Fontes, 2008.

GIACOIA JUNIOR, Oswaldo. Foucault. Em Tempo, Marília, v. 6, p. 9-20, ago. 2004.

GIACOIA JUNIOR, Oswaldo. Notas sobre direito, violência e sacrifício. Doispontos, Curitiba, v. 5 , n. 2 , p. 33-47, out. 2008a.

GIACOIA JUNIOR, Oswaldo. Sobre direitos humanos na era da bio-política. Kriterion, Belo Horizonte, n. 118, p. 267-308, dez. 2008b.

HARDT, Michel; NEGRI, Antonio. Império. Rio de Janeiro: Record, 2001. 
HARDT, Michel; NEGRI, Antonio. Multidão. Rio de Janeiro: Record, 2005.

HOBBES, Thomas. Leviatã ou a matéria, forma e oder de um Estado eclesiástico e civil. Tradução: Rosina D’Angina. São Paulo: Ícone, 2014.

HOBSBAWM, Eric J. Nações e nacionalismo desde 1780. Rio de Janeiro: Paz e Terra, 2002.

HOBSBAWM, Eric J.; RANGER, Terence. A invenção das tradições. Rio de Janeiro: Paz e Terra, 2008.

JULIOS-CAMPUZANO, Alfonso de; LUCAS, Doglas Cesar; SANTOS, André Leonardo Copetti. Direitos Humanos, Imigração e Diversidade: Dilemas da vida em movimento na sociedade contemporânea. Ijuí, RS: Unijuí, 2016.

KANT, Immanuel. A paz perpétua e outros opúsculos. Lisboa: Edições 70, 1995.

LÖWY, Michael. Por um novo internacionalismo. Lutas Sociais, São Paulo, n. 5, p. 97-106, 1998.

LUCAS, Doglas Cesar; SANTOS, André Leonardo Copetti. População e governamentalidade: a mobilidade humana (des)controlada. In: JULIOS-CAMPUZANO, Alfonso de; LUCAS, Doglas Cesar; SANTOS, André Leonardo Copetti. Direitos humanos, imigração e diversidade: dilemas da vida em movimento na sociedade contemporânea. Ijuí, RS: Unijuí, 2016.

REDIN, Giuliana. Direito de imigrar: direitos humanos e espaço público na sociedade contemporânea. 2010. Tese (Doutorado em Direito) - Pontifícia Universidade Católica do Paraná, Curitiba, 2010.

Como citar: HOFFMAM, Fernando; MARQUES, Juciélle Flores. Estado-nação, biopolítica e fenômeno migratório: o reconhecimento frente ao cenário biopolítico. Revista do Direito Público, Londrina, v. 15, n. 1, p. 114-136, abr. 2020. DOI: 10.5433/24157-108104-1.2020v15n1p. 114. ISSN: $1980-511 \mathrm{X}$

Recebido em: 04/02/2019

Aprovado em: 11/03/2019 